Int. Agrophys., 2022, 36, 13-26

INTERNATIONAL

\title{
Impacts of soil organic carbon and tillage systems on structural stability as quantified by the high energy moisture characteristic (HEMC) method**
}

\author{
Elham Farahani ${ }^{1}$, Hojat Emami ${ }^{1}{ }^{*} *$, Peyman Keshavarz ${ }^{2}$ \\ ${ }^{1}$ Department of Soil Science, Ferdowsi University of Mashhad, 9177948974, Mashhad, Iran \\ ${ }^{2}$ Soil and Water Research Department, Khorassan Razavi, Agriculture and Natural Resources Center 9165966416, Mashhad, Iran
}

Received December 13, 2021; accepted January 13, 2022

\begin{abstract}
The impact of different tillage systems on the structural stability of the soil as quantified by high energy moisture characteristics has not been studied to date in the semi-arid region of northeastern Iran. Therefore, in this research, the effects of conventional, reduced, and no-tillage treatments under wheat-corn crop rotation on the organic carbon content, soil organic carbon stocks and microbial biomass carbon and also the aggregate stability of a clay loam soil (Aridisol, in USDA soil classification) were evaluated in northeastern Iran. Measurements were made at two depths $(0-15$ and $15-30 \mathrm{~cm})$ three years after the establishment of experiment. Aggregate stability was determined using the high energy moisture characteristics, mean weight diameter and the percentage of water-stable aggregates. The high energy moisture characteristics stability indices (i.e. structural index, volume of drainable pores, and slope at the inflection point of high energy moisture characteristics) were higher for the slow (on average $0.053 \mathrm{hPa}^{-1}, 0.4 \mathrm{~g} \mathrm{~g}^{-1}$, and $0.022 \mathrm{hPa}^{-1}$ for structural index, volume of drainable pores and slope at the inflection point, respectively) than the fast wetting rate (on average $0.014 \mathrm{hPa}^{-1}, 0.2 \mathrm{~g} \mathrm{~g}^{-1}$, and $0.012 \mathrm{hPa}^{-1}$ for structural index, volume of drainable pores and slope at the inflection point, respectively). The modal suction was higher for the fast (18.61 $\mathrm{hPa}$ in average) than for the slow wetting rate $(7.63 \mathrm{hPa}$ in average). Organic carbon, soil organic carbon stocks and microbial biomass carbon were higher for no-tillage as compared with the reduced and conventional treatments, due to the use of a cover crop (clover) and because crop residues were retained in this system. The treatments contained greater organic carbon, soil organic carbon stocks and microbial biomass carbon (no-tillage at both depths and reduced at a depth of $0-15 \mathrm{~cm}$ ) showed mainly high stability ratios and indices, regardless of
\end{abstract}

*Corresponding author e-mail: hemami@um.ac.ir

**This work was partially supported by a grant (25812) from Ferdowsi University of Mashhad (2020-2021). the wetting rate. The values of modal suction were lower in the treatments which contained greater organic carbon, soil organic carbon stocks, and microbial biomass carbon, which results in a stable soil structure. The no-tillage system, which produced the maximum organic carbon and soil organic carbon stock among the tillage systems, showed the highest amounts of mean weight diameter $(0.15 \mathrm{~mm})$, and water-stable aggregates (92\%). Our findings revealed that the high energy moisture characteristics method was highly sensitive to macroaggregate stability in water.

Keyw ords: aggregate slaking, microbial activity, soil management, structural stability, Aridisols

\section{INTRODUCTION}

Conservation agriculture including no-tillage or reduced tillage with stubble retention, is promoted as a set of agricultural practices that have the potential to increase the soil organic carbon (SOC) pool and have a positive effect on aggregate stability. Conservation tillage, especially the no-tillage system creates macroaggregates, prevents organic carbon decomposition by microbes and extends organic carbon storage in aggregates. Hence, investigating the effects of different land use and management systems, in particular, tillage and crop residue retention, may lead to a better understanding of soil function and properties (Wu et al., 2019). For example, Wu et al. (2019) found that

(C) 2022 Institute of Agrophysics, Polish Academy of Sciences 
the percentages of the macroaggregate fractions under the no-till system with crop residue retention, were increased significantly in the semi-arid region of northwestern China.

No-tillage systems have a tendency to conserve terrestrial organic carbon storage and increase the sequestration of carbon from the atmosphere into carbon stocks. Organic carbon encourages microbial activity and produces polysaccharides and carbohydrates, which stabilize soil aggregates and create macropores (Caravaca et al., 2002). The effects of tillage systems on soil organic carbon stocks may be related to the movement of soil organic carbon to deeper layers due to tillage practices, which may promote organic carbon stabilization (Wertebach et al., 2017). More aggregate stability in NT systems as compared with CT may be attributed to the higher organic matter content in the NT soils and the development of inter- and intra-aggregate cohesion forces due to the absence of tillage, which is known to stabilize aggregates (Mamedov et al., 2020). SOC management through optimized agricultural practices is an important strategy for improving soil ecosystem processes. Increasing the SOC storage level not only affects the atmospheric carbon content but it also ameliorates the soil physical, chemical, and biological functions and properties. While low amounts of SOC causes degradation in the soil structure and decreases the water infiltration rate and aggregate stability, especially in arid and semi-arid regions of the world, which also increases soil erosion and soil loss (Blanco-Canqui et al., 2013). The application of the no-tillage system increased the soil aggregate stability under wheat-corn and wheat-legume rotations in a semi-arid Mediterranean region of Turkey (Celik et al., 2012). Reduced tillage increases the accumulation of SOC, and could create greater values of MWD, and WSA, (Abdollahi et al., 2014).

Structural stability is usually determined by the aggregates in the soil (Singer and Munns, 2002), which in turn are held together by stabilizing agents. Therefore, the important binding role of the soil organic matter content has been extensively investigated (Duiker, 2006). Soil microbial biomass and respiration are affected by soil management, different land use regimes and management techniques can modify organic carbon contents because of soil microorganism interactions. The microbial community may include a wide range of individual species, which are capable of responding heterogeneously to environmental changes. Soil microorganisms may lose their potency due to ecosystem disturbances and become unable to perform nutrient cycling and soil structure maintenance (Kara and Baykara, 2014).

Different methods have been developed to investigate the stability of soil aggregates through their capability to remain intact when exposed to stresses such as water forces (rainfall or irrigation), and the mechanical forces of traffic and cultivation (Blanco-Canqui and Lal, 2006). The high energy moisture characteristic (HEMC) is also usually applied to evaluate the stability of the soil structure, along with wellknown methods of aggregate stability estimation (Mamedov and Levy, 2013). The HEMC method was studied to assess the stability of the soil structure in arid/semi-arid regions (Mamedov et al., 2020). The HEMC method was first suggested by Childs (1940), but some other researchers modified and standardized it to quantify the experimental and modeling methods; this group includes Collis-George and Figueroa (1984), Pierson and Mulla (1989), and Levy and Mamedov (2002). Based on the modified approach, soil aggregates are wetted in two sets (one slowly and quickly), then their water characteristic curves are determined at a low range of matric suction, i.e. 0 to $50 \mathrm{hPa}$ high energies, HEMCs. Finally, an index of aggregate stability is obtained by evaluating the differences in HEMCs between the slow and fast sets of wetted aggregates. Moreover, a comparison of the stability of the aggregates is made by using the fast structural index or the fast to slow structural index ratio, i.e. stability ratio $(S R)$ (Levy and Mamedov, 2002; Mamedov and Levy, 2013).

Iran is located in an arid and semi-arid region of the world with low soil organic carbon content (less than $1 \%$ in $61.6 \%$ of the agricultural soils (Moshiri et al., 2017). Since soil organic carbon promotes microbial activity, conservation tillage practices could be used to influence the microbial community which controls the process of the stabilization of aggregates. Therefore, the relationships between soil aggregate stability and organic carbon content and stocks may play an essential role in soil functional capacity under different tillage systems in the arid and semi-arid region of Iran. The objective of this study was to investigate the effects of conventional and conservation tillage systems which are associated with the effects of different organic carbon and microbial biomass on the stability indices of the soil structure of an agricultural soil in the arid/semi-arid region of northeastern Iran, based on the HEMC method, and water stable aggregates.

\section{MATERIALS AND METHODS}

Experimental plots of tillage practices and wheat-corn rotations were established in 2017 at the Agricultural and Natural Resources Research Centre in Khorasan Razavi province, northeastern Iran (36 ${ }^{\circ} 13^{\prime} 24^{\prime \prime} \mathrm{N}$ latitude, 59 $38^{\prime} 19^{\prime \prime} \mathrm{E}$ longitude, and $1003 \mathrm{~m}$ altitude above sea level). The mean annual temperature and precipitation in the study area during the experiment were $17.5^{\circ} \mathrm{C}$, and $230 \mathrm{~mm}$, respectively. The soil was classified as a typical Haplocambid soil according to the USDA classification system (Soil Survey Staff, 2014).

Three tillage systems were included in the study; CT (conventional tillage), RT (reduced tillage), and NT (no-tillage) were arranged in a randomized complete block design with three replications. The width and length of each plot were $3 \mathrm{~m}$ (equal to the width of the cultivation machines) and $25 \mathrm{~m}$, respectively; i.e. the plot size was $75 \mathrm{~m}^{2}$. A drip tape irrigation system was applied in the field.

Cultivation and crop rotation factors from the beginning of the experiment (2017) until our sampling time (2020) included the following: 
1. Wheat was cultivated and harvested in Nov 2017 and June 2018, respectively.

2. After wheat harvesting, clover was sown as a cover crop using a Wintersteiger seeder in no tillage treatment plots in July 2018, and the fallow treatment was applied to the CT and RT plots. The clover was harvested (with $5 \mathrm{~cm}$ stubs on the soil surface) using a mower in May 2019.

3. Corn was sown and harvested in June and October 2019, respectively.

4. Thereafter, the wheat was cultivated and harvested in November 2019 and June 2020, respectively.

NT treatment consisted of the complete elimination of any ploughing, crop residues were also left behind and mixed with the soil surface to a minimum extent. The seeds in NT were sown using a direct drill planter and ordinary row planter for wheat and corn, respectively. RT consists of using a double-disc harrow and then a drill planter, hence crop residues were retained in the plots and mixed with the soil by harrow disc during field preparation for the next planting. CT treatment was applied using a mouldboard plough and harrow disc, and the stubs remained in the plots.

In the $\mathrm{CT}$ and RT systems, pneumatic precision sowing machines and row planters were used for the cultivation of corn and wheat, respectively. The seeds in the NT were sown using a direct drill and ordinary row planters for wheat and corn, respectively. The wheat and corn were harvested using a combine and a chopper, respectively.

Phosphorous (P) and potassium (K) fertilizers (superphosphate triple, $200 \mathrm{~kg} \mathrm{ha}^{-1}$, and potassium sulphate $200 \mathrm{~kg} \mathrm{ha}^{-1}$ for wheat and superphosphate triple $150 \mathrm{~kg} \mathrm{ha}^{-1}$, and potassium sulphate $150 \mathrm{~kg} \mathrm{ha}^{-1}$ for corn) were applied based on soil testing and fertilizer recommendation. In the CT system, after mouldboard ploughing and tandem disking, the $\mathrm{P}$ and $\mathrm{K}$ fertilizers were applied manually to the plots, and mixed with soil during the second disking. In the RT system, after one pass of the offset harrow disk, the $\mathrm{P}$ and $\mathrm{K}$ fertilizers were spread by hand on the plots, and then mixed with soil during the second disking. In the NT system, the planter was equipped with fertilizer kits, which insert $\mathrm{P}$ and $\mathrm{K}$ fertilizers under and beside the seeds. Nitrogen fertilizer (urea 400 and $350 \mathrm{~kg} \mathrm{ha}^{-1}$ for wheat and corn, respectively) were applied manually in two doses: the first $75-100 \mathrm{~kg} \mathrm{ha}^{-1}$ of urea was added before the second irrigation, and the rest of the urea was applied at the tillering and stem extension stages for wheat, and also at the 4-8 leaves stage for corn. A complete set of micronutrients (Extra Mix fertilizer), were also added with foliar spray $\left(1.5 \mathrm{~kg} \mathrm{ha}^{-1}\right)$ at the tillering stage for wheat and at the 6-8 leaves stage for corn.

The inherent soil properties of the untreated soil (i.e. the original soil) were determined before the establishment of the plots at a depth of 0-30 cm, in September 2017. Some characteristics of the soil are shown in Table 1 . The soil texture was measured using the pipette method (Gee and Bauder, 1986), and the levels of calcium carbonate were determined using reverse titration (Sparks et al., 1992). Organic carbon and total nitrogen were measured using wet oxidation (Walkley and Black, 1934), and Kjeldahl (Bremner and Mulvaney, 1982) methods, respectively. Electrical conductivity (EC) and $\mathrm{pH}$ were estimated using the saturated paste extraction method. $\mathrm{Ca}$ and $\mathrm{Mg}$ concentrations were then determined using titration by EDTA, and $\mathrm{Na}$ concentration was determined using a flame photometer apparatus (Richards, 1954).

Table 1. Selected physical and chemical properties of the original soil

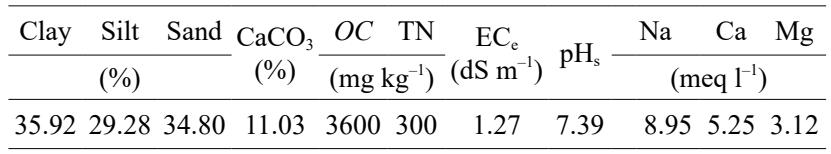

$O C$ - organic carbon, $\mathrm{TN}$ - total nitrogen, $\mathrm{EC}_{\mathrm{e}}-$ electrical conductivity of the saturated extract, $\mathrm{pH}_{\mathrm{s}}-\mathrm{pH}$ of the saturated paste.

In addition, undisturbed soil core samples, and soil aggregates were collected from two depths $(0-15$ and $15-30 \mathrm{~cm})$ of the tillage treatments in July 2020. Then, the soil chemical properties were measured, this included organic carbon $(O C)$ (Walkley and Black, 1934), total nitrogen (TN) (Bremner and Mulvaney, 1982), C:N ratio, $\mathrm{pH}$, and EC (in a soil:water ratio of 1:2) (Richards, 1954) (Table 2). The soil organic carbon stock (SOC stock) was determined using the following formula (Wertebach et al., 2017):

$$
\text { SOC stock }\left(t C h a^{-1}\right)=O C B D \text { depth interval, }
$$

where: $O C$ is the organic carbon content in the soils $\left(\mathrm{g} \mathrm{C} \mathrm{kg}^{-1}\right), B D$ is the soil bulk density $\left(\mathrm{kg} \mathrm{ha}^{-1}\right)$, and the depth interval is $0.15 \mathrm{~m}$.

Table 2. Mean comparison of the chemical (EC, pH, OC, SOC stock, TN, C:N) and biological (MBC) soil properties of the treatments

\begin{tabular}{|c|c|c|c|c|c|c|c|c|}
\hline Treatments & $\begin{array}{c}\mathrm{EC} \\
\left(\mathrm{dS} \mathrm{m}^{-1}\right)\end{array}$ & $\mathrm{pH}$ & $O C$ & $\frac{\mathrm{MBC}}{\left(\mathrm{mg} \mathrm{kg}^{-1}\right)}$ & $\mathrm{TN}$ & $\mathrm{C}: \mathrm{N}$ & $\begin{array}{c}\text { SOC stock } \\
\left(\mathrm{tC} \mathrm{ha}^{-1}\right)\end{array}$ & $\begin{array}{c}B D \\
\left(\mathrm{~g} \mathrm{~cm}^{-3}\right) \\
\end{array}$ \\
\hline$\overline{\mathrm{CT}_{0-15}}$ & $0.348^{\mathrm{b}}$ & $8.08^{\mathrm{ab}}$ & $4615^{\mathrm{bc}}$ & $2780^{\mathrm{b}}$ & $324.3^{\mathrm{ab}}$ & $14.515^{b}$ & $10.73^{\mathrm{b}}$ & $1.56^{\mathrm{a}}$ \\
\hline $\mathrm{CT}_{15-30}$ & $0.370^{\mathrm{ab}}$ & $8.19^{\mathrm{a}}$ & $2015^{\mathrm{d}}$ & $1551^{\mathrm{c}}$ & $310.3^{\mathrm{ab}}$ & $6.495^{\mathrm{c}}$ & $4.45^{\mathrm{c}}$ & $1.47^{\mathrm{a}}$ \\
\hline $\mathrm{RT}_{0-15}$ & $0.407^{\mathrm{ab}}$ & $7.89^{b c}$ & $6630^{\mathrm{b}}$ & $4118^{\mathrm{ab}}$ & $329.0^{\mathrm{ab}}$ & $20.145^{\mathrm{ab}}$ & $15.72^{\mathrm{ab}}$ & $1.60^{\mathrm{a}}$ \\
\hline $\mathrm{RT}_{15-30}$ & $0.376^{\mathrm{ab}}$ & $8.00^{\mathrm{b}}$ & $3575^{\mathrm{c}}$ & $2120^{\mathrm{b}}$ & $234.5^{\mathrm{c}}$ & $15.529^{b}$ & $8.48^{\mathrm{bc}}$ & $1.55^{\mathrm{a}}$ \\
\hline $\mathrm{NT}_{0-15}$ & $0.461^{\mathrm{a}}$ & $7.75^{\mathrm{c}}$ & $6890^{\mathrm{ab}}$ & $4308^{a b}$ & $371.0^{\mathrm{a}}$ & $18.865^{\mathrm{ab}}$ & $16.58^{\mathrm{ab}}$ & $1.60^{\mathrm{a}}$ \\
\hline $\mathrm{NT}_{15-30}$ & $0.397^{\mathrm{ab}}$ & $7.88^{\mathrm{bc}}$ & $8778^{\mathrm{a}}$ & $4898^{\mathrm{a}}$ & $294.0^{\mathrm{b}}$ & $29.712^{\mathrm{a}}$ & $21.37^{\mathrm{a}}$ & $1.62^{\mathrm{a}}$ \\
\hline
\end{tabular}

$\mathrm{CT}$ - conventional tillage, RT - reduced tillage, NT - no-tillage, MBC - microbial biomass carbon, C:N - OC to TN ratio, SOC stock - soil organic carbon stock, $B D$ - bulk density. Means in a column followed by the same letter are not significantly different ( $\mathrm{p}<0.05)$.

Other explanations as in Table 1. 
The gravimetric water contents were also measured at a depth of $0-30 \mathrm{~cm}$, with a $5 \mathrm{~cm}$ interval, during the sampling period.

In order to achieve $0.5-1.0 \mathrm{~mm}$ aggregates, the soil samples were air-dried and gently sieved. After that, about $15 \mathrm{~g}$ of the aggregates were set in PVC cores with a diameter of $35 \mathrm{~mm}$ and a height of $40 \mathrm{~mm}$ to establish a $25 \mathrm{~mm}$ thick layer in an aggregates bed. In order to evaluate the high energy moisture characteristic (HEMC) data, the aggregates were arranged in two sets of wetting rates, fast and slow, with three replicates. In the fast wetting set, each core was abruptly saturated with distilled water and was left flooded for $24 \mathrm{~h}$ (Poch and Antunez, 2010). In the slow wetting set, a slow saturation procedure was performed by applying matric suction values of $25,20,15,10,5$, and $0 \mathrm{hPa}(60 \mathrm{~min}$ equilibration time for each matric suction value) to the cores which were placed in a sandbox apparatus (Bearden, 2001). Then, the moisture characteristic curves of both fast and slow wetted cores were evaluated at a low matric suction range of 0 to $50 \mathrm{hPa}(0,5,10,15,20,25,30,35,40,45$ and $50 \mathrm{hPa})$, using a sandbox. The core samples were placed in a sandbox and exposed to 11 matric suction values from 0 to $50 \mathrm{hPa}$ at $5 \mathrm{hPa}$ intervals. The cores were weighed after equilibration for each matric suction value, then all of them were ovendried and weighed to obtain the values of the gravimetric water contents corresponding to the matric suction values.

The structural stability indices of the soils were determined by fitting the modified van Genuchten model (Eq. (2)) to the measured HEMC ( $\theta$ vs. $h)$ data (Mamedov and Levy, 2013) using the non-linear method of the Solver Tool (Wraith and Or, 1998) in Microsoft Excel:

$$
\theta(h)=\theta_{r}+\left(\theta_{s}-\theta_{r}\right)\left[1+(\alpha h)^{n}\right]^{\left(\frac{1}{n}-1\right)}+A h^{2}+B h+C,
$$

where $\theta_{r}$ and $\theta_{s}$ are the residual and saturated water contents $\left(\mathrm{g} \mathrm{g}^{-1}\right), \alpha\left(\mathrm{hPa}^{-1}\right)$ and $n(-)$ are the empirical parameters, and $A\left(\mathrm{hPa}^{-2}\right), B\left(\mathrm{hPa}^{-1}\right)$, and $C\left(\mathrm{~g} \mathrm{~g}^{-1}\right)$ are the quadratic coefficients (Pierson and Mulla, 1989) for the better-fitting of the model to the data. The residual water content $\left(\theta_{r}\right)$ in the HEMC method is not the real $\theta_{r}$, in other words, it is the pseudo $\theta_{r}$, and therefore, the trend of $\theta_{r}$ may not be predictable.

The specific water capacity function $(C(\theta)=|d \theta / d h|$, $\mathrm{hPa}^{-1}$ ) was calculated with the 1st derivative of Eq. (2) using Eq. (3):

$$
\begin{aligned}
& C(\theta)=\left(\theta_{s}-\theta_{r}\right)\left[1+(\alpha h)^{n}\right]^{\left(\frac{1}{n}-1\right)}\left(\frac{1}{n}-1\right) \\
& (\alpha h)^{n}\left(\frac{n}{\left[h\left\{1+(\alpha h)^{n}\right\}\right]}\right)+2 A h^{2}+B .
\end{aligned}
$$

The modal suction $\left(h_{\text {modal }}, \mathrm{hPa}\right)$ corresponds to matric suction value at the peak of $C(\theta)$, it was estimated using Eq. (4) (Hosseini et al., 2015):

$$
h_{\text {modal }} \approx \frac{1}{\alpha}\left(\frac{n-1}{n}\right)^{\frac{1}{n}} .
$$

The volume of drainable pores $(V D P)$ is the integral of the area under the specific water capacity curve. The $V D P$ was obtained using Eq. (3) by determining the area bound by the pore shrinkage line (i.e. $2 \mathrm{Ah}+\mathrm{B}$ ) and the specific water capacity curve. The structural index $\left(S I, \mathrm{hPa}^{-1}\right)$ was described in terms of the ratio of $V D P$ to $h_{\text {modal }}$ at fast and slow wetting rates. Moreover, the ratio of fast to slow $S I$ values (defined as the stability ratio $(S R)$ ) was used to compare the aggregate stability of the treatments. A greater $S R$, close to 1 , shows the higher structural stability of the soil (Collis-George and Figueroa, 1984):

$$
\begin{aligned}
& S I=\frac{V D P}{h_{\text {modal }}}, \\
& S R=\frac{S I_{\text {Fast }}}{S I_{\text {Slow }}} .
\end{aligned}
$$

Similarly, the ratio of fast to slow $V D P$ values $(V D P R)$ was calculated using Eq.(7) to determine the aggregate stability (Levy and Mamedov, 2002):

$$
V D P R=\frac{V D P_{\text {Fast }}}{V D P_{\text {Slow }}} .
$$

The absolute value of the slope at the inflection point $\left(S_{\mathrm{i}}\right.$, $\mathrm{hPa}^{-1}$ ) of HEMC was also evaluated using Eq.8 (Hosseini et al., 2015):

$$
S_{i}=|d \theta / d h|_{i}=\left(\theta_{s}-\theta_{r}\right) n \alpha\left(\frac{n-1}{2 n-1}\right)^{\left(\frac{2 n-1}{n}\right)} .
$$

The structural stability ratio $\left(S_{\mathrm{i}} R\right)$ which is similar to the $S R$, was also calculated:

$$
S_{i} R=\frac{S_{i-\text { Fast }}}{S_{i-\text { Slow }}} .
$$

The percentage of water-stable aggregates was obtained using the wet sieving method (Kemper and Rosenau, 1986):

$$
W S A=\frac{A-S}{W-S} 100
$$

where $A$ is the mass of stable aggregates (g), $S$ is the sand mass $(\mathrm{g})$ on the sieve and $W$ is the sum of aggregate and sand mass $(\mathrm{g})$.

The mean weight diameter $(M W D, \mathrm{~mm})$ was measured using the wet sieving method with nested sieves included in the set of 4, 2, 1, 0.5, 0.25 and $0.125 \mathrm{~mm}$ sieves used, as a measure of aggregate stability, which was determined using the following equation (van Bavel, 1950):

$$
M W D=\sum_{i=1}^{n} X_{i} W_{i},
$$

where $X_{\mathrm{i}}(\mathrm{mm})$ is the mean diameter of two adjacent fractions and $W_{\mathrm{i}}$ is the ratio of the mass of the aggregate fraction to the total mass of the soil.

Soil sampling for microbial biomass carbon (MBC) measurement was performed using moist soils, at the water content close to field capacity, in July 2020 after wheat harvest. Moist soil samples were used for the MBC measurement and a particular aggregate size was not considered. The $\mathrm{MBC}$ was measured using the fumigation incubation method 
of Jenkinson and Powlson (1976). In general, the method involves the chloroform $\left(\mathrm{CHCl}_{3}\right)$ fumigation of moist soil samples for $0-20$ days at $25^{\circ} \mathrm{C}$ and the determination of the $\mathrm{CO}_{2}-\mathrm{C}$ emitted in fumigated versus unfumigated soil.

The data were analysed using a general linear model (GLM) based on a randomized complete block design combined with a factorial experiment, with three replications per treatment. Analyses were made using the SPSS 24 software. ANOVA (simple effects and multiple comparisons) were made using the Duncan test at a significance level of $p<0.05$. The relationship between aggregate stability indices (i.e. $S R, V D P R, S_{i} R, S I_{- \text {Fast }}, S I_{\text {-Slow }}, V D P_{\text {Fast }}, V D P_{\text {Slow }}$, $S_{i-\text { Fast }}$, and $S_{i \text {-Slow }}, h_{\text {modal-Fast }}$ and $h_{\text {modal-Slow }}$ ) and chemical, biological and physical properties including $O C, \mathrm{C}: \mathrm{N}$ ratio, $\mathrm{MBC}, M W D$, and $W S A \%$ were determined using Pearson pair-wise correlations.

\section{RESULTS AND DISCUSSION}

The organic carbon $(O C)$ content of the original soil was $0.36 \%$ (Table 1), which is low but normal in the arid/ semi-arid regions of Iran because $61.6 \%$ of agricultural soils contain less than one percent $O C$ (Moshiri et al., 2017). A mean comparison between some of the chemical and biological soil properties of the treatments are presented in Table 2. The amounts of $O C$ and soil organic carbon (SOC) stocks varied to a substantial extent between the treatments. Regardless of soil depth, NT showed a 56.7 and $150 \%$ increase in SOC stocks in comparison with the RT and CT treatments, respectively. RT also had 59\% more SOC stocks than CT. SOC stocks were not calculated using the original soil, because the $B D$ and soil depth intervals data were not accessible, therefore only the variation in SOC stocks among the treatments was discussed. The mean comparisons of $B D$ showed that they were not statistically significant.

The increase in $O C$ in the NT as compared to the original soil, were up to 92 and $144 \%$ (from 0.36 to 0.69 and $0.88 \%$ ) at depths of 0-15 and $15-30 \mathrm{~cm}$, respectively (Tables 1 and 2). Also, an $O C$ accumulation of $83 \%$ (from 0.36 to $0.66 \%$ ) as compared to the original soil occurred in RT at a depth of $0-15 \mathrm{~cm}$. Gwenzi et al. (2009) reported that the $O C$ value at $0-15 \mathrm{~cm}$ under no-till and minimum tillage systems was higher than that of conventional tillage, therefore no-till and minimum tillage improved the structural stability of the soil and also carbon sequestration in the semi-arid region of Zimbabwe. Wertebach et al. (2017) demonstrated that SOC concentrations and stocks increased in abandoned croplands due to the lack of tillage operations, while tillage practices led to the depletion of topsoil SOC stock of different soil types. The $O C$ in RT at a subsurface depth (15$30 \mathrm{~cm}$ ) did not change in comparison with the original soil, presumably this is due to the inappropriate addition of crop residues in the soil at the subsurface layer of this treatment. An increase in $O C$ of up to $28 \%$ (from 0.36 to $0.46 \%$ ) as compared to the original soil in the surface of CT $(0-15 \mathrm{~cm})$ may be attributed to the presence of crop root residues in the soil. However, in the subsurface of CT $(15-30 \mathrm{~cm})$ a $44 \%$ decrease in $O C$ as compared with the original soil was found (from 0.36 to $0.20 \%$ ), probably because of a lack of crop residue addition and decomposition of organic matter due to tillage practices (Celik et al., 2012).

An increment of the $O C$ and SOC stocks in no-till and RT systems was related to crop residues retention and the mixture with soil in these treatments as compared with CT, in which crop residues were removed after harvest in the CT treatment and only the stubs were retained. Also, the $O C$ content and SOC stocks in NT were higher than in RT, because the cover crop was cultivated and crop residues were minimally mixed with soil in NT, therefore microbial decomposition was limited, and the organic matter supply was increased.

Wheat-corn crop rotation was applied in this research, which had high $\mathrm{C}: \mathrm{N}$ ratios of residues $(80: 1$ and $57: 1$, for wheat and corn residues, respectively (e.g. Wortman et al., 2006)). Therefore, the amounts of $O C$ and $\mathrm{C}: \mathrm{N}$ of the soils increased in the NT and RT treatments due to the remaining plant residues (Table 2). The accumulation of organic matter in soils is normally due to crop residue retention in the field, which increases both the soil organic carbon and the C:N ratio (Yamakura and Sahunalu, 1990).

In semi-arid areas soils usually have a low organic matter content, the clay content was found to have more of an effect on soil structure, and clay particles can generate organic-mineral complexes, which results in the accumulation of organic matter increases (Levy and Mamedov, 2002). The clay content was also high in the studied soil (Table 1), which has the potential to contribute to an increase in organic matter accumulation in the treatments including crop residue retention in comparison with the original soil.

The fitting of the modified van Genuchten model (Eq. (2)) to the HEMC data was outstanding with $R^{2}$ values of 0.96 to 0.99 . The mean values of the fitting parameters for the treatments for fast and slow wetting rates have been presented in Table 3. In the HEMC method, water retention is measured within macropores in a certain size range $(\mathrm{pF}=0-1.6)$ and thus the HEMC model parameters may differ from the entire water retention model parameters $(\mathrm{pF}=0-7)$, resulting mainly in micropores and mesopores. The saturated water content $\left(\theta_{s}\right)$ predicted by the modified van Genuchten model significantly increased with increases in the $O C$ and SOC stocks for the treatments (Table 2) involving both fast and slow wetting rates, and a maximum value of $\theta_{s}$ (mean of the fast and slow wetting $=0.779 \mathrm{~g} \mathrm{~g}^{-1}$ ) was attributed to the no-tillage treatment at a $15-30 \mathrm{~cm}$ depth $\left(\mathrm{NT}_{15-30}\right)$ which contained the highest amount of $O C$ and SOC stocks among the treatments studied $\left(\approx 0.88 \%\right.$ of $O C$ and $\approx 21.4 \mathrm{t} \mathrm{C} \mathrm{ha}^{-1}$ of $S O C$ stocks). A decrease in $\theta_{s}$ with the reduction in $O C$ confirmed that soil porosity decreased due to the destruction of soil structure and pores. Organic agents play the role of 
a cement between the soil particles and therefore stabilize soil aggregates and structure, as a consequence macropores have a greater tendency to form (Wertebach et al., 2017).

Amounts of $\theta_{s}$ for the slow wetting rate treatments were higher than those for the fast wetting rate treatments in all treatments studied, due to the slaking of the aggregates in the fast wetting procedure. However, the $\theta_{r}$ value in the fast wetting rate treatment was greater than that of the slow wetting rate treatment in all treatments studied, because most of the macropores were broken down during the fast wetting procedure. The highest $\theta_{r}$ value belonged to the CT system at a depth of $0-15 \mathrm{~cm}$ in the slow wetting treatment, also the $\theta_{r}$ value was not statistically different between the treatments for the fast wetting rate, however, CT had a greater $\theta_{r}$ value than RT and NT, regardless of the soil depth sampled. CT included micropores for the most part and hence microaggregates, presumably because of the maximum tillage practices as compared to RT and NT.

The parameter $\alpha$ represents the water released near the saturated suction or air entry value; a decrement in the $\alpha$ value means that the desaturation process starts at higher matric suction values. In fast wetting, regardless of the depth, NT had higher $\alpha$ values than RT and CT. The maximum $\alpha$ value was attributed to $\mathrm{NT}_{15-30}$ with an $0.88 \%$ of $O C$ and $21.4 \mathrm{t} \mathrm{Cha}^{-1}$ of SOC stocks, and the lower $\alpha$ values were assigned to the CT treatment with the lowest $O C$ and SOC stocks (Tables 2 and 3). For entire water retention, with predominant micro-and mesopores, Emami and Astaraei (2012) reported that the air-entry value increased with an increase in the concentration of micropores. Also, $\mathrm{NT}_{0-15}$ and $\mathrm{RT}_{0-15}$ showed great $\alpha$ values after $\mathrm{NT}_{15-30}$, because they also contained high $O C$ contents and SOC stocks, and in turn, stable soil structures. Mamedov et al. (2020) reported that changing the management practices from conventional tillage (CT) to no-tillage (NT) increased parameter $\alpha$ and aggregate stability due to an increase in the organic matter content of NT as opposed to CT, in a semi-arid region of Turkey. In slow wetting, the difference in $\alpha$ values among the treatments was not statistically significant. The parameter $n$ governs the shape of the water retention curve in the desaturation zone. An increase in $n$ with the increase in $O C$ demonstrates that the slope of the desaturation zone would be boosted by a slow wetting rate due to the stabilizing role of $O C$ on soil aggregates. This reflects the properties of the most stable aggregates (i.e. assigned to $\mathrm{NT}_{15-30}$ with $0.88 \%$ of $O C$ and $21.4 \mathrm{t} \mathrm{C} \mathrm{ha}^{-1}$ of SOC stocks) which are desaturated in the lower range of matric suction as compared to the other treatments. Also, in the fast wetting treatment, the maximum $n$ value was found in $\mathrm{NT}_{15-30}$. Emami and Astaraei (2012) also demonstrated that changing the pore-size distribution due to soil amendments affected water retention, thereby changing the retention curve shape parameter $(n)$.

The water retention curves of the fitting model to HEMC data at a depth of 0-15 and $15-30 \mathrm{~cm}$ for the various treatments studied are presented in Figs 1a and 1c, respectively. The results showed that the wetting rate has notable effects on the shape and steepness of HEMCs and model parameters in all of the treatments (Fig. 1 and Table 3). The differences in the fast and slow wetting curves can be assigned to aggregate slaking in the fast wetting procedure, because of the hydration of clay particles, entrapped air impact, and irregular swelling (Mamedov et al., 2017). It is important to emphasize that the wetting speed of the aggregates is slower. In other words, for the slow wetting rate, the lower impacts are generated by water occupation in the spaces of the aggregates rather than air. Therefore, the pressure within the aggregates and the clay expansion rate is lower, aggregate slaking is also decreased (Silva et al., 2014).

Evaluation of the water retention curves shows that the degradation of the soil's physical condition often changes the shape of these curves especially with regard to decreases in the saturated and inflection points (Dexter, 2004). The shape of the water retention curves altered as a result of different soil tillage systems (Fig. 1). This phenomenon is due to the variation in the organic carbon content found in the different management systems, which changes the shape parameters of the water retention curves and, as a consequence, the pore-size distribution (Silva et al., 2014). Based on Mamedov et al. (2010), the HEMC may be divided into three categories: (1) matric suction of 3 to $12 \mathrm{hPa}$ (relative to $1000-250 \mu \mathrm{m}$ pores), (2) matric suction of 12 to $24 \mathrm{hPa}$ (relative to $250-125 \mu \mathrm{m}$ pores), and (3) matric suction of 24 to $50 \mathrm{hPa}$ (relative to $125-60 \mu \mathrm{m}$ pores). The qualitative interpretation of the HEMC indicated that the aggregate stability changed in various ranges of matric potential, corresponding to macro- and microporosity within the studied

Table 3. Mean comparison of the fitting parameters of HEMCs data modelling of the water retention curve of the treatment plots

\begin{tabular}{|c|c|c|c|c|c|c|c|c|c|c|c|c|c|c|}
\hline \multirow{2}{*}{ Treatments } & \multicolumn{2}{|c|}{$\theta_{r}\left(\mathrm{~g} \mathrm{~g}^{-1}\right)$} & \multicolumn{2}{|c|}{$\theta_{S}\left(\mathrm{~g} \mathrm{~g}^{-1}\right)$} & \multicolumn{2}{|c|}{$n(-)$} & \multicolumn{2}{|c|}{$\alpha\left(\mathrm{hPa}^{-1}\right)$} & \multicolumn{2}{|c|}{$A\left(\mathrm{hPa}^{-2}\right)$} & \multicolumn{2}{|c|}{$B\left(\mathrm{hPa}^{-1}\right)$} & \multicolumn{2}{|c|}{$C\left(\mathrm{~g} \mathrm{~g}^{-1}\right)$} \\
\hline & fast & slow & fast & slow & fast & slow & fast & slow & fast & slow & fast & slow & fast & slow \\
\hline $\mathrm{CT}_{0-15}$ & $0.241^{\mathrm{a}}$ & $0.118^{\mathrm{a}}$ & $0.399^{c}$ & $0.469^{c}$ & $2.648^{\mathrm{a}}$ & $1.911^{\mathrm{b}}$ & $0.0328^{\mathrm{c}}$ & $0.0899^{\mathrm{ab}}$ & $910^{-6 \mathrm{ab}}$ & $4410^{-6 a}$ & $-7910^{-5 b}$ & $-0.0043^{\mathrm{b}}$ & $0.0225^{\mathrm{b}}$ & $0.0821^{\mathrm{a}}$ \\
\hline $\mathrm{CT}_{15-30}$ & $0.234^{\mathrm{a}}$ & $0.012^{\mathrm{c}}$ & $0.415^{\mathrm{c}}$ & $0.464^{\mathrm{c}}$ & $2.208^{\mathrm{a}}$ & $1.867^{\mathrm{b}}$ & $0.0310^{\mathrm{c}}$ & $0.1061^{\mathrm{a}}$ & $310^{-6} \mathrm{ab}$ & $610^{-6 c}$ & $2110^{-7} \mathrm{ab}$ & $-910^{-7 a}$ & $1410^{-6 \mathrm{~b}}$ & $0.0286^{\mathrm{b}}$ \\
\hline $\mathrm{RT}_{0-15}$ & $0.185^{\mathrm{a}}$ & $0.107^{\mathrm{a}}$ & $0.551^{\mathrm{b}}$ & $0.714^{\mathrm{b}}$ & $2.188^{\mathrm{a}}$ & $1.886^{\mathrm{b}}$ & $0.0603^{\mathrm{ab}}$ & $0.0873^{\mathrm{ab}}$ & $0.0^{\mathrm{b}}$ & $1310^{-6 c}$ & $4210^{-6 a b}$ & $410^{-5 a}$ & $0.0815^{\mathrm{a}}$ & $0.0001^{\mathrm{b}}$ \\
\hline $\mathrm{RT}_{15-30}$ & $0.097^{\mathrm{a}}$ & $0.086^{\mathrm{b}}$ & $0.407^{\mathrm{c}}$ & $0.464^{\mathrm{c}}$ & $2.039^{\mathrm{a}}$ & $1.883^{\mathrm{b}}$ & $0.0291^{\mathrm{c}}$ & $0.0982^{\mathrm{ab}}$ & $410^{-6} \mathrm{ab}$ & $2910^{-6 \mathrm{~b}}$ & $1910^{-7 \mathrm{ab}}$ & $-0.0029^{b}$ & $0.0178^{\mathrm{b}}$ & $0.0629^{a}$ \\
\hline $\mathrm{NT}_{0-15}$ & $0.166^{\mathrm{a}}$ & $0.103^{\mathrm{ab}}$ & $0.543^{b}$ & $0.711^{\mathrm{b}}$ & $2.101^{\mathrm{a}}$ & $1.947^{\mathrm{b}}$ & $0.0563^{\mathrm{b}}$ & & $110^{-5}$ a & $1510^{-6 \mathrm{bc}}$ & $1610^{-5} \mathrm{ab}$ & $610^{-7 \mathrm{a}}$ & $0.0815^{\mathrm{a}}$ & $0.0001^{\mathrm{b}}$ \\
\hline $\mathrm{NT}_{15-30}$ & $0.248^{\mathrm{a}}$ & $0.043^{\mathrm{bc}}$ & $0.737^{\mathrm{a}}$ & $0.822^{\mathrm{a}}$ & $3.059^{\mathrm{a}}$ & $2.291^{\mathrm{a}}$ & $0.0683^{\mathrm{a}}$ & $0.0897^{\mathrm{ab}}$ & $410^{-6} \mathrm{ab}$ & $510^{-6 \mathrm{c}}$ & $7910^{-5}$ a & $-310^{-7} \mathrm{a}$ & $110^{-5 \mathrm{~b}}$ & $0.0136^{\mathrm{b}}$ \\
\hline
\end{tabular}

$\theta_{S}-$ saturated water content, $\theta_{r}-$ residual water content, $n$ - empirical parameters which control the position of the water retention curve, $\alpha$-empirical parameters which control the steepness of the water retention curve, $A, B$, and $C$-quadratic coefficients to improve model fitting. Means in a column followed by the same letter are not significantly different $(\mathrm{p}<0.05)$. Other explanations as in Tables 1 and 2. 

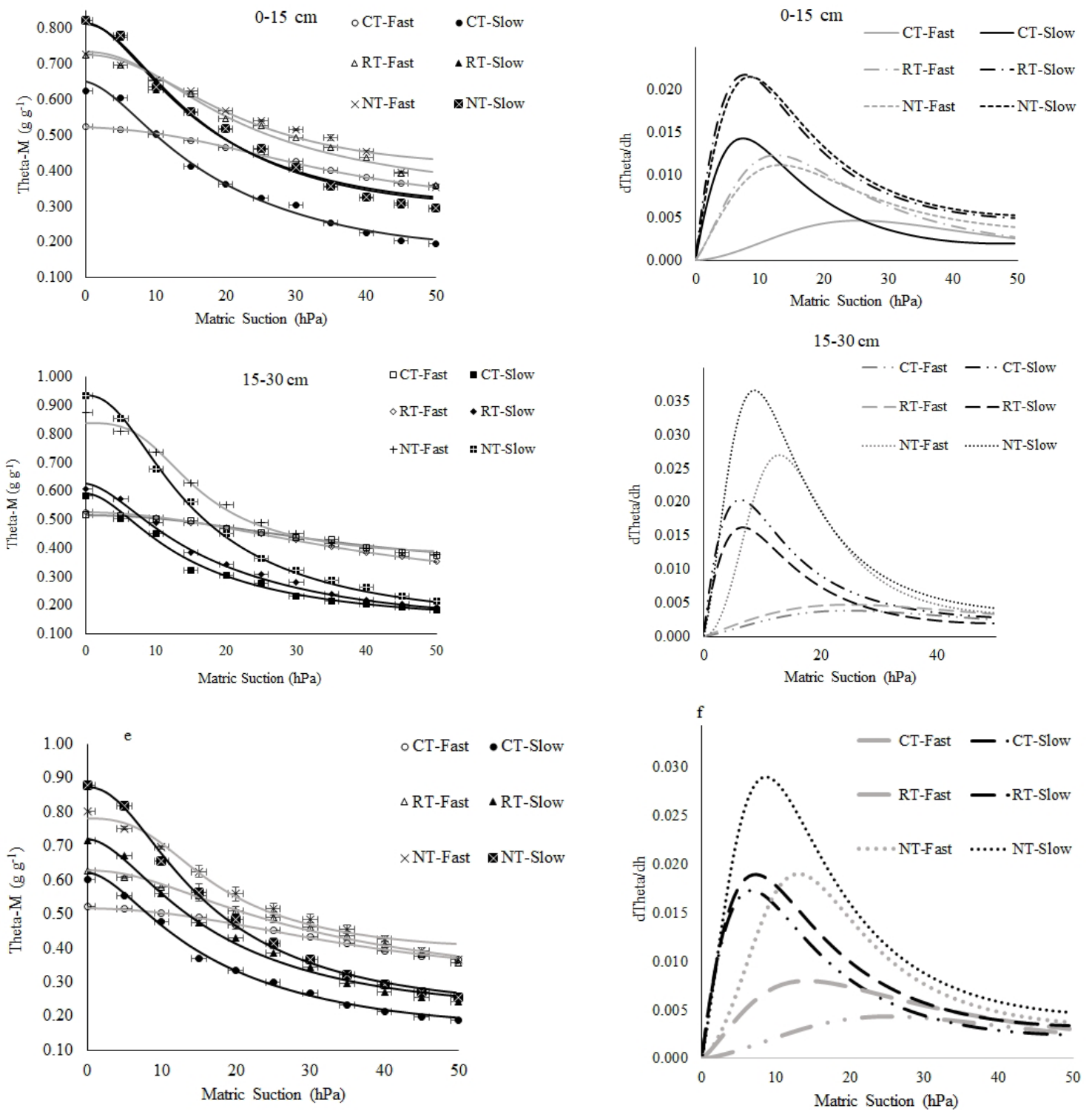

Fig. 1. High energy moisture characteristic (HEMC) curves, and specific water capacity functions at depths of 0-15 cm (a), and (b), and $15-30 \mathrm{~cm}(\mathrm{c})$, and (d) for the treatments subjected to both slow and fast wetting; the mean of both depths of the HEMC curves (e), and specific water capacity functions (f) of CT, RT and NT. The continuous curves in (a), (c), and (e) are the fittings of the modified van Genuchten model; grey lines and no-fill markers - fast wetting; black lines and filled markers - slow wetting. CT - conventional tillage, RT - reduced tillage, NT - no-tillage, Error bars indicate \pm 1 standard error.

macropore range (Amézketa,1999; Mamedov and Levy, 2013), thereby allowing for a better understanding of the mechanisms responsible for aggregate disintegration such as; the entrapped air effect, slaking, etc.

Based on Figs 1a and 1c, for the slow wetting treatment, regardless of depth, the highest water contents at saturation and low matric suction values of HEMC (0-24 hPa) were attributed to NT as compared to RT and CT, and the water contents sharply decreased with increasing matric suction $(24-50 \mathrm{hPa})$. In the NT system, organic matter decomposition was limited and the amount of $O C$ and SOC stocks increased as compared to the RT and CT treatments (Table 2). Enhanced soil aeration due to ploughing operations increases organic matter decomposition in the soil (Wertebach et al., 2017). This implies that the NT treatment included more structural pores, macropores of $>250 \mu \mathrm{m}$ and mesopores of $250-125 \mu \mathrm{m}$, created by high $O C$ and SOC stocks. Also, the lowest water contents at saturated and low matric suction $(<24 \mathrm{hPa})$ were found in the CT treatment, and water contents during the matric suction increment $(24-50 \mathrm{hPa})$ gradually decreased. In the CT system, macropores were not created, and weak structure and mostly micropores $(125-60 \mu \mathrm{m})$ occur because of the low values of $O C$ and SOC stocks as compared with RT and NT. At a depth of 0-15 cm (Fig. 1a), RT also showed high water contents at saturated and low matric suction values of 
HEMC (0-24 hPa), this was similar to NT, because it had a high amount of $O C$ and $S O C$ stocks, and in turn contained more structural pores, (macropores of $>250 \mu \mathrm{m}$ ).

In the case of fast wetting; an almost similar trend was observed and NT (at both depths), and $\mathrm{RT}_{0-15}$ had higher water contents than the other treatments, and the slope of the curves was more gradual than the slow wetting treatment, this was probably due to the destruction of the soil structure in the fast wetting procedure. In addition, $\mathrm{RT}_{15-30}$, CT (at both depths) had a very mild slope of water retention curves for the fast wetting in particular, which could be related to low $O C$ and SOC stocks in these treatments, therefore, unstable soil structures had more structural collapses during fast wetting. In conventional tillage with no crop residues (i.e. only the stubs), organic matter was not added to the soil, therefore there was no continuous supply of $O C$ to the soil, which is the reason for the lower stability of aggregates in this treatment. Wu et al. (2017) and Amjadi et al. (2021) demonstrated that organic matter can increase aggregate stability.

Management systems that lead to aggregate disintegration in fast wetting rates, usually cause the release of fine sand and silt particles, which are related to the clogging of soil pores, resulting in a reduction in soil permeability. Farahani et al. (2020) found that the migration of fine particles into the soil pores led to pore clogging, the destruction of aggregates, and also to a reduction in pore size. However, if the aggregate stability of the soil increases under a fast wetting rate, they are presumably resistant to heavy rain and are less susceptible to slaking (Silva et al., 2014).

Fig. $1 \mathrm{~b}$ and $1 \mathrm{~d}$ showed the specific water capacity functions $\left(C(\theta)=|d \theta / d h|, \mathrm{hPa}^{-1}\right)$ of fast and slow wetting conditions at depths of $0-15$ and $15-30 \mathrm{~cm}$, respectively. The maximum specific water capacities for slow and fast wetting were also attributed to NT (at both depths) this is inconsistent with the results of the water retention curves, and $\mathrm{RT}_{0-15}$ which contain the highest $O C$ and SOC stocks. This reflects less slaking and entrapped air in the most stabilized aggregates of the treatments that contained high $O C$ and SOC stocks. Analysis of $C(\theta)$ shows that when there are no stabilizing agents, the wetting rate had an important effect on the curve shape, and then on the stability indices and model parameters of $\mathrm{RT}_{15-30}$, and $\mathrm{CT}$ (at both depths).

In this research, we focused on the soil microbial community, i.e. microbial biomass carbon (MBC), as well as $O C$ present in the treatments. The land-use type influences the composition of the microbial communities and their contribution to aggregate stabilization (Umer and Rajab, 2012). Since the fresh plant residues produce cohesive compounds, increase microbial activity, and are a source of organic carbon (Poch and Antunez, 2010), the crop residues in the NT and RT treatments probably contributed to an increase in microbial activity. The addition of organic matter to soils promotes the formation of microbial biomass to a greater extent than the conventional management of soils (Six et al., 2006), which may be a possible reason for increasing $\mathrm{MBC}$ in NT and RT treatments as compared to CT. As a consequence, NT treatment at both depths $\left(\mathrm{NT}_{0-15}\right.$, $\mathrm{NT}_{15-30}$ ), and $\mathrm{RT}_{0-15}$ produced the most macropores because of the role of $\mathrm{MBC}$ in stabilizing the aggregates, and hence the HEMC stability indices and WSA\% (Figs 2 and 3).

Plant production may increase the soil microbial biomass, which in turn increases the tendency for microbial sequestration of organic matter into the soil organic carbon pool (Wertebach et al., 2017). The soil carbon pool related to the microbial community determines the process of the stabilization of aggregates, and the resistance to fast wetting as the major mechanism of aggregate stability is driven by microorganisms (Guidi et al., 2013). Similarly, Hosseini et al. (2015) reported that the infection of soil by fungal endophytes enhances the stability of soil pores, due to the formation of more stable aggregates, better water repellency, and the fine physical quality of the soil. The soil microbial community dynamics were influenced by the tillage system, and the arbuscular mycorrhizal fungi density and composition were modified by tillage practices, which may increase the stability of the soil aggregate (Duchicela et al., 2013). Cessation of tillage practices in no-tillage systems allows the soil to recover from some of the negative effects of disturbance. Research into no-tillage systems shows that the recovery of soil properties negatively influenced by tillage practices seems to be slow, and that the response time may differ according to the particular chronosequence and with the specific soil property (Duchicela et al., 2013).

The mean values of the structural stability indices of HEMC are shown in Table 4. A reduction in volume drainable pores $(V D P)$ was obtained for fast wetting as compared to slow wetting because of the slaking of the fast-wetted aggregates and the entrapped air effect. Alternating conventional tillage (CT) to no-tillage (NT) increased VDP in fast and slow wetting rates (Fig. 1, and Table 4). Thus, fast wetting changes the size of aggregates to smaller sizes and these changes followed the trend of $\mathrm{CT}>\mathrm{RT}>\mathrm{NT}$, regardless of depth. The VDP decreases as the extent of aggregate breakdown increases, and the smallest pore size occurred in the fast wetting treatment using organic farm aggregates (Pierson and Mulla, 1989). The mean diameter of the aggregates after fast wetting at a suction range from 0 to $50 \mathrm{hPa}$ in NT was higher than the corresponding value for the RT and CT treatments which reflects the greater aggregate stability in no-tillage systems.

When the content of organic matter increases, the number of macroaggregates, and consequently VDP increases, as opposed to soils that have a low organic carbon content the aggregates may be destroyed as a result of entrapped air within the aggregates. Entrapped air within the aggregates leads to slaking and the destruction of coarse aggregates during the fast wetting process, which is an important mechanism for decreasing the structural stability of the soil (Amezketa, 1999). Changes in soil structure after the breakdown of aggregates, 

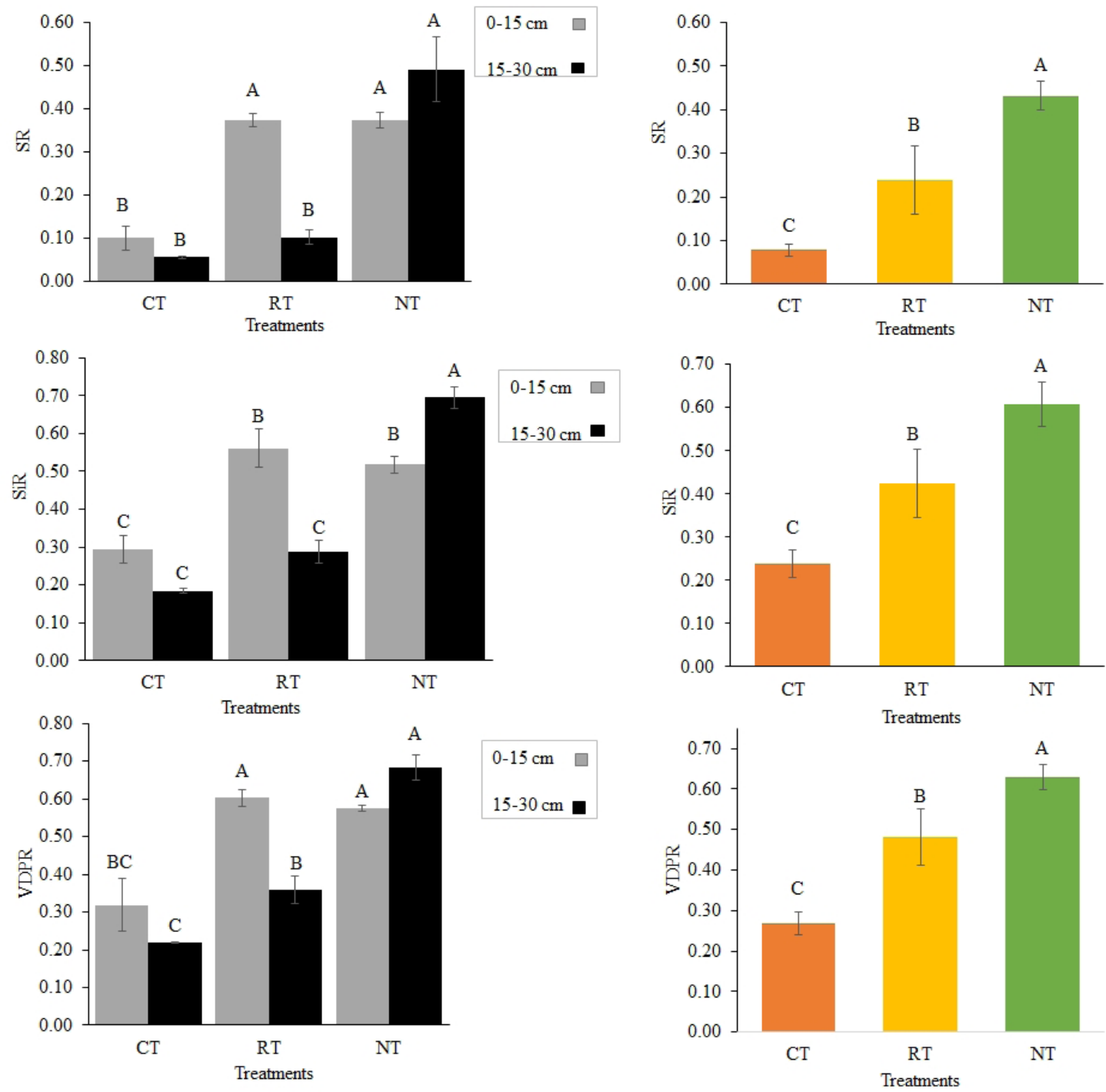

Fig. 2. Values of the stability ratio $(S R)$, (a) the stability ratio similar to $S R$ as the ratio of $S_{\mathrm{i}}$ in fast and slow wetting $\left(S_{\mathrm{i}} R\right)$, (b) the ratio of fast to slow $V D P$ values $(V D P R)$, (c) and the mean of both depths of the ratios (d), (e), and (f) of CT, RT and NT of HEMC in the treatments. Means in a column followed by the same letter are not significantly different $(\mathrm{p}<0.05)$. Other explanations as in Fig. 1.

usually results in the rearrangement of small particles. In turn, this causes pore-size distribution to progress toward a greater number of smaller pores (from macro to micropores), and thus decreases $V D P$ and increases the value of modal suction $\left(h_{\text {modal }}\right)$ (Mamedow and Levy, 2013; Gholoubi et al., 2019).

The structural stability index $(S I)$ value represents a narrow range of pore sizes which is related to the extent of aggregate porosity (Mamedov et al., 2020). The slope of HEMC at the inflection point $\left(S_{i}\right)$ was considered to be an index of structural stability, which is similar to Dexter's S-theory. Greater values of $S I, \mathrm{~S}_{\mathrm{i}}$, and $V D P$, and a low value of $h_{\text {modal }}$ were found in the $\mathrm{NT}_{15-30}$ treatment for the slow wetting rate, due to the higher values of $\theta_{s}$ and $\alpha$ for the slow wetting curves, respectively (Table 3 ). This finding demonstrated the role that organic matter plays as a cementing agent versus the destructive forces caused by wetting and may create stable macropores, also fewer aggregates break

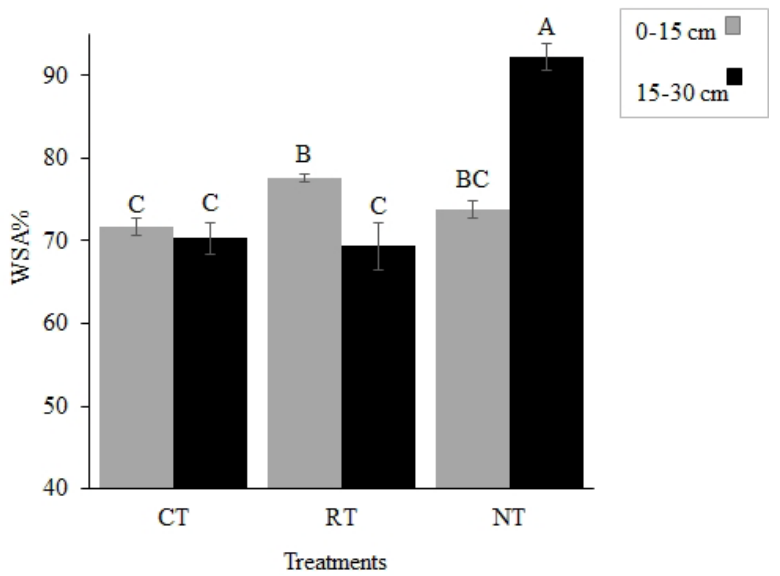

Fig. 3. Water-stable aggregates $(W S A \%)$ in different treatments at two depths $(0-15$ and $15-30 \mathrm{~cm})$. Means in a column followed by the same letter are not significantly different $(\mathrm{p}<0.05)$. Other explanations as in Fig. 1. 
Table 4. Mean comparison of structural stability indices of HEMC method

\begin{tabular}{|c|c|c|c|c|c|c|c|c|}
\hline \multirow{2}{*}{ Treatments } & \multicolumn{2}{|c|}{$h_{\text {modal }}(\mathrm{hPa})$} & \multicolumn{2}{|c|}{$S I\left(\mathrm{hPa}^{-1}\right)$} & \multicolumn{2}{|c|}{$S_{\mathrm{i}}\left(\mathrm{hPa}^{-1}\right)$} & \multicolumn{2}{|c|}{$V D P\left(\mathrm{~g} \mathrm{~g}^{-1}\right)$} \\
\hline & fast & slow & fast & slow & fast & slow & fast & slow \\
\hline $\mathrm{CT}_{0-15}$ & $24.90^{\mathrm{a}}$ & $7.54^{\mathrm{ab}}$ & $0.0035^{\mathrm{c}}$ & $0.0348^{c}$ & $0.0043^{\mathrm{cd}}$ & $0.0146^{\mathrm{b}}$ & $0.085^{\mathrm{c}}$ & $0.263^{\mathrm{c}}$ \\
\hline $\mathrm{CT}_{15-30}$ & $24.47^{\mathrm{a}}$ & $6.25^{\mathrm{b}}$ & $0.0032^{\mathrm{c}}$ & $0.0580^{\mathrm{ab}}$ & $0.0037^{\mathrm{d}}$ & $0.0204^{b}$ & $0.079^{c}$ & $0.362^{\mathrm{b}}$ \\
\hline $\mathrm{RT}_{0-15}$ & $12.38^{\mathrm{b}}$ & $7.67^{\mathrm{ab}}$ & $0.0211^{\mathrm{b}}$ & $0.0564^{\mathrm{ab}}$ & $0.022^{\mathrm{b}}$ & $0.0218^{\mathrm{b}}$ & $0.261^{\mathrm{b}}$ & $0.433^{\mathrm{b}}$ \\
\hline $\mathrm{RT}_{15-30}$ & $24.37^{\mathrm{a}}$ & $6.84^{\mathrm{ab}}$ & $0.0042^{\mathrm{c}}$ & $0.0432^{\mathrm{bc}}$ & $0.0047^{\mathrm{c}}$ & $0.0166^{\mathrm{b}}$ & $0.102^{\mathrm{c}}$ & $0.291^{\mathrm{c}}$ \\
\hline $\mathrm{NT}_{0-15}$ & $13.03^{\mathrm{b}}$ & $8.46^{\mathrm{ab}}$ & $0.0192^{b}$ & $0.0518^{b}$ & $0.011^{\mathrm{bc}}$ & $0.0215^{\mathrm{b}}$ & $0.250^{\mathrm{b}}$ & $0.435^{\mathrm{b}}$ \\
\hline $\mathrm{NT}_{15-30}$ & $12.52^{\mathrm{b}}$ & $9.02^{\mathrm{a}}$ & $0.0348^{\mathrm{a}}$ & $0.0745^{\mathrm{a}}$ & $0.026^{\mathrm{a}}$ & $0.0365^{\mathrm{a}}$ & $0.433^{\mathrm{a}}$ & $0.632^{\mathrm{a}}$ \\
\hline
\end{tabular}

$h_{\text {modal }}$ - modal suction, $S I$ - structural index, $S_{\mathrm{i}}$ - slope at the inflection point of HEMC, VDP - volume of drainable pores. Means in a column followed by the same letter are not significantly different $(\mathrm{p}<0.05)$. Other explanations as in Tables 1 and 2.

down in the $\mathrm{NT}_{15-30}$ treatment. Mamedov et al. (2017) found a positive exponential relationship between $S I$ and parameter $\alpha$ for aggregates of three sizes $(0.25-0.5,0.5-1$, and $1-2 \mathrm{~mm})$ from four semi-arid soils treated with polyacrylamide. They emphasized that an increase in $\alpha$ implies an increase in aggregate stability and resistance to slaking by wetting.

$S_{i-\text { Fast }}$ significantly decreased from 0.035 in $\mathrm{NT}_{15-30}$ to 0.003 in CT at both depths, this indicated that the slaking of aggregates occurred during fast wetting. A fast wetting rate increases $h_{\text {modal }}$ and decreases $V D P$ by reducing pore sizes and results in decreases in SI. Water penetrates and weakens the outer aggregate surfaces in the fast wetting process, while the entrapped air pressure increases at the same time. When this pressure exceeds a certain threshold, the cohesive strength of the weakened layers is reduced, and the air escapes, this results in aggregate breakdown.

Lower $S_{\mathrm{i}-\text { Fast }}$ values revealed that aggregates break down and small pores formed during fast wetting, and greater values of $S_{\mathrm{i}}$ correspond to improved aggregate stability. The results showed that $S_{i-F a s t}$ values and $S R$ in $\mathrm{RT}_{15-30}, \mathrm{CT}_{0-15}$, and $\mathrm{CT}_{15-30}$ were significantly decreased compared to NT at both depths and $\mathrm{RT}_{0-15}$, this is probably due to low $O C$ and $S O C$ stocks. Organic compounds are important agents in stabilizing aggregates, they are adsorbed on the surface of soil particles and bond them together (Alami et al., 2000). It seems likely that organic compounds encouraged fungal activity which improved the stability of aggregate in fast wetting due to the water repellency of soil aggregates as a result of fungal hydrophobic substances (Chenu and Cosentino, 2011).

Moreover, the stability ratio of $S_{\mathrm{i}}$ in fast and slow wetting $\left(S_{\mathrm{i}} R\right)$ and the ratio of fast to slow $V D P(V D P R)$ values as additional structural stability indices/ratios of HEMC are presented in Fig. 2. It may be stated that although the maximum aggregate stability $(S R)$ value is equal to 1 , in our research, the $S R$ values were less than 0.50 , this is probably because the management practices were only continued for 3 years. The significant positive correlation of SR with $S_{i} R$ $\left(\mathrm{r}=0.93, \mathrm{p}<0.01\right.$, Table 5) confirms that $S_{i} R$ could be used as an alternative index of structural stability. The highest values of $S R, S_{i} R$, and $V D P R$ were attributed to NT at both depths, and to the $\mathrm{RT}_{0-15}$ treatment with more $O C$ and $S O C$ stocks, as mentioned previously. Higher values of $S R$ suggest the greater stability of soil aggregates (Mamedov et al., 2020). The $S R$ values for fast and slow wetted aggregates
(Fig. 2a) indicate that the susceptibility of the aggregate to slaking depends closely on the tillage system used as well as the $O C$ and $S O C$ stocks and that the effects of fast wetting on the slaking of aggregate in NT at both depths, and also for the $\mathrm{RT}_{0-15}$ treatment was minimal and the distribution of macropores for the slow and fast wetting rates were similar. This finding was due to the higher $O C$ and SOC stocks and MBC for the NT treatment at both depths, and also for the $\mathrm{RT}_{0-15}$ treatment which probably formed a hydrophobic coating film around the aggregates which slowed down aggregate soaking, therefore decreasing the sensitivity to slaking in fast wetting rate. By contrast, for other treatments with lower $O C$ and SOC stocks and MBC, slaking significantly reduced drainable pores and $S R$.

In this way, the CT system may affect the soil aggregate stability by decreasing the organic matter (binding agent) content, and the microbial activity, i.e. $\mathrm{MBC}$, which results in greater amounts of dispersed clay due to mechanical disruption (Amezketa, 1999). A close positive correlation between $S R$ and $S I_{\text {-Fast }}(\mathrm{r}=0.91, \mathrm{p}<0.01$, Table 5) indicated that $S R$ is mainly determined by $S I_{\text {-Fast }}$ rather than $S I_{\text {-Slow }}$. For the NT treatment at both depths, and the $\mathrm{RT}_{0-15}$ treatment, the organic carbon contents significantly increased the $S R$ (Fig. 2a), due to increases in $S I_{\text {-Fast }}$. Also, as an index for aggregate stability, $V D P R$ was significantly influenced by the $O C$ and SOC stocks. The significant linear correlation between $V D P R$ and $V D P_{\text {Fast }}(\mathrm{r}=0.9, \mathrm{p}<0.01$, Table 5) suggests that the organic matter content has a more substantial impact on $V D P_{\text {Fast }}$ than $V D P_{\text {Slow }}$ and therefore increases the degree of structural stability. The presence of organic carbon encourages microbial activity and produces compounds of polysaccharides and carbohydrates which stabilize soil aggregates (Caravaca et al., 2002). The significant correlations of $\mathrm{SR}, V D P R$, and $S_{\mathrm{i}} \mathrm{R}$ with $O C, \mathrm{MBC}$, and the C:N ratio (Table 5) support this finding.

The percentage of water-stable aggregates (WSA\%), and the mean weight diameter $(M W D)$ were also determined in the treatments as they are common methods used to assess soil structural stability (Figs 3 and 4), this is due to the fact that soil pore size and its distribution is associated with aggregate size (Mamedov et al., 2017). The results of $W S A \%$ and $M W D$ confirmed the results of the HEMC method, it was determined that the highest value of $W S A \%$ and $M W D$ were produced by the $\mathrm{NT}_{15-30}$ treatment which had the highest $O C$ content and 


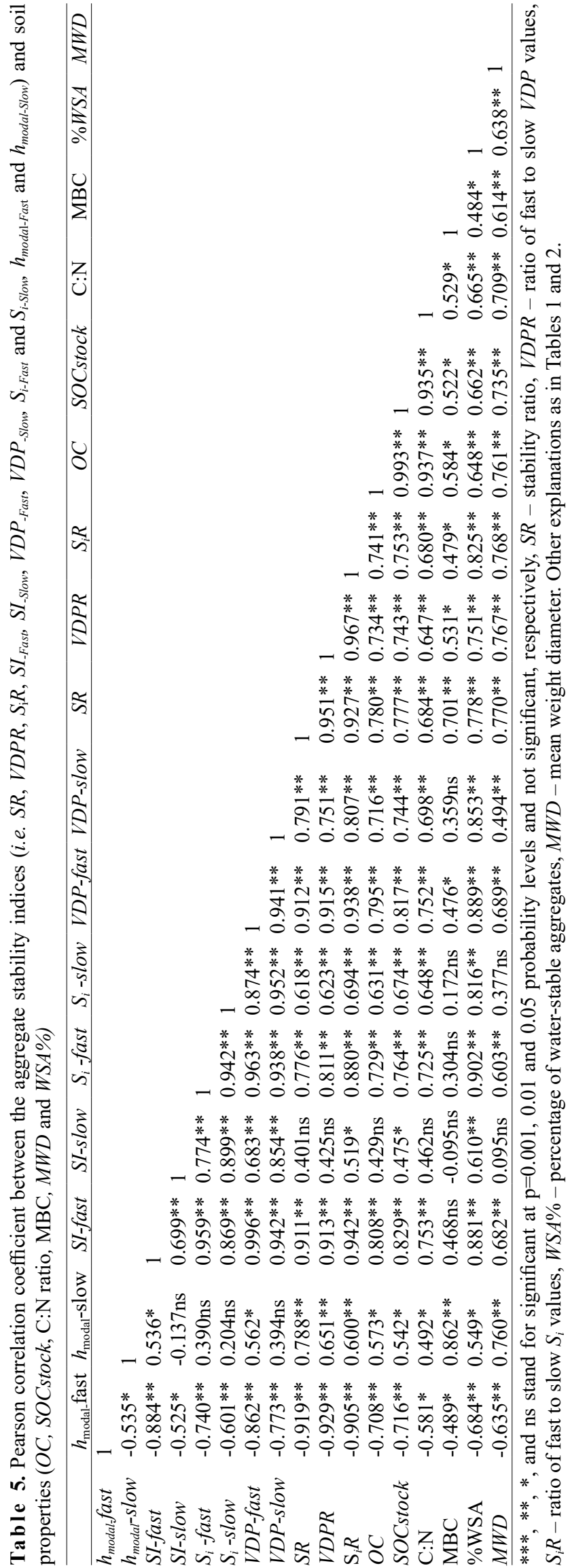

SOC stocks (Figs 3, 4 and Table 2). Both the $\mathrm{RT}_{0-15}$ and $\mathrm{NT}_{0-15}$ treatments showed high $W S A \%$ (Fig. 3), and they also had high contents of $O C$ and $S O C$ stocks (Table 2), which may be a potential reason to create a high degree of aggregate stability. The $\mathrm{pH}$ value may also be effective on soil structure, for example at lower $\mathrm{pH}$ values, the activity of $\mathrm{H}^{+}$causes aggregation of clays, and binding between soil organic matter and clay surfaces encourages flocculation (Gholoubi et al., 2019). According to Table 2, the lower $\mathrm{pH}$ values for the NT treatment (at both depths), and also for the $\mathrm{RT}_{0-15}$ treatment tended to produce more stable aggregates than the other treatments with higher $\mathrm{pH}$ values. A high amount of $W S A \%$ may lead to the formation of large soil pores between the stable aggregates (Mamedov et al., 2017; Farahani et al., 2018), which is consistent with the results of the water retention curves of HEMC. Moreover, the $\mathrm{RT}_{15-30}$ and $\mathrm{CT}_{15-30}$ treatments produced the lowest $M W D$ (Fig. 4), which contained minimum $O C$ and SOC stocks (Table 2). Wu et al (2019) studied four tillage systems which included conventional tillage and no-tillage with and without straw retention in the semi-arid western Loess Plateau, northwestern China and found that conventional tillage treatment without straw retention produced the lowest soil organic carbon and $M W D$ results.

The accumulation of organic matter in soils is normally due to crop residue retention in the field, which increases soil organic carbon levels and the $\mathrm{C}: \mathrm{N}$ ratio (Yamakura ad Sahunalu, 1990). Significant correlation coefficients $(\mathrm{P}<0.01)$ were found between $W S A \%$ and $M W D$ and most of the HEMC indices (Table 5). The high positive correlation for $O C$ and $\mathrm{C}: \mathrm{N}$ with most of the structural stability indices (i.e. SR, VDPR, $\left.S_{i} R, S I, V D P, S_{\mathrm{i}}, h_{\text {modal }}\right)$ indicated that the HEMC indices and also $W S A \%$ and $M W D$ increase by increasing $O C$ and $\mathrm{C}: \mathrm{N}$. The significant positive correlation found between $\mathrm{MBC}$ and the structural stability ratios (i.e. $S R, V D P R, S_{\mathrm{i}} R$ ) and also $W S A \%$ and $M W D$ in our study is supported by the findings of Guidi et al. (2013)

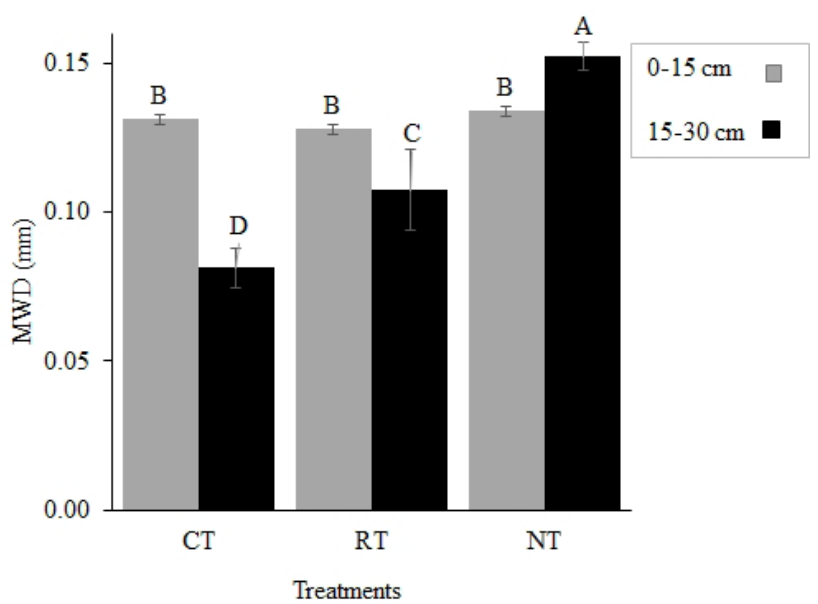

Fig. 4. Mean weight diameter $(M W D)$ in different treatments at two depths $(0-15$ and $15-30 \mathrm{~cm})$. Means in a column followed by the same letter are not significantly different $(\mathrm{p}<0.05)$. Other explanations as in Fig. 1. 
and Hosseini et al. (2015), which indicates that a positive increment in MBC could induce the stabilization of the aggregates. Tisdall and Oades (1982) have shown that the stability of macroaggregates can be improved by the application of decomposable organic material.

\section{CONCLUSIONS}

1. Studying the effect of soil management practices on aggregate stability is essential in semi-arid regions that have low organic carbon contents and soil organic carbon stocks. Therefore, this research assessed the effects of three different tillage practices (conventional tillage, reduced tillage, and no-tillage) on soil aggregate (structure) stability through the high energy moisture characteristics method, and the percentage of water-stable aggregates and microbial biomass carbon in an agricultural soil. Our findings demonstrated that most changes in soil structural stability were related to organic carbon content and soil organic carbon stocks. The change from conventional to reduced and no-tillage systems led to an increase in organic carbon accumulation, i.e. soil organic carbon stocks, which is important in the agricultural soils of Iran (arid and semi-arid regions with a low organic matter content). In addition, the highest organic carbon content and microbial activity in the no-tillage system created the most stable aggregates.

2. In general, the results indicated that the high energy moisture characteristics indices (structural index, stability ratio, structural stability ratio, and volume of drainable pores values) had a positive correlation with organic carbon and microbial activity. Therefore, a lack of organic carbon and a suboptimal microbial community especially in arid regions decreases soil aggregate stability. These findings may be associated with the size of the predominant macroaggregates and the range of the pressure head in the high energy moisture characteristics method, which only takes into account soil structural pores (0 to $50 \mathrm{hPa}$ matric suction values, i.e. macropores). Future studies may include a more prolonged experiment and the minimum amount of residue material required to support organic carbon and soil structural stability.

Conflict of interests: The authors declare that no conflict of interests.

\section{REFERENCES}

Abdollahi L. and Munkholm L.J., 2014. Tillage system and cover crop effects on soil quality: I. Chemical, mechanical, and biological properties. Soil Sci. Soc. Am. J., 78(1), 262270, https://doi.org/10.2136/sssaj2013.07.0301

Alami Y., Achouak W., Marol C., and Heulin T., 2000. Rhizosphere soil aggregation and plant growth promotion of sunflowers by an exopolysaccharide-producing Rhizobium sp. strain isolated from sunflower roots. Appl. Environ. Microbiol., 66(8), 33933398, https://doi.org/10.1128/aem.66.8.3393-3398.2000

Amezketa E., 1999. Soil aggregate stability: A Review. J. Sustainable Agric., 14(2-3), 83-151, https://doi.org/10.1300/J064v14n02_08
Amjadi M., Emami H., Farahani E., and Gholoubi A., 2021. Effect of vermicompost and urban waste compost on stability of aggregates by high energy moisture characteristic curve. J. Agric. Sci. Techn., 23(6), 1379-1393.

Bearden B.N., 2001. Influence of arbuscular mycorrhizal fungi on soil structure and soil water characteristics of Vertisols. Plant Soil, 229(2), 245-258, https://doi.org/10.1023/A:1004835328943

Blanco-Canqui H. and Lal H., 2006. Tensile strength of aggregates. Encyclopedia of Soil Science, vol. 45-48. The Ohio State University, Columbus, OH, USA.

Blanco-Canqui H., Shapiro C.A., Wortmann C.S., Drijber R.A., Mamo M., Shaver T.M., and Ferguson R.B., 2013. Soil organic carbon: The value to soil properties. J. Soil Water Conserv., 68(5), 129-134, https://doi.org/10.3390/su13073799

Bremner J. and Mulvaney C., 1983. Nitrogen - Total. In: Methods of Soil Analysis (Ed. A. Page). ASA/SSSA, Madison, https://oi.org/10.2134/agronmonogr9.2.2ed.c31

Caravaca F., Hernandez T., Garcia C., and Roldan A. 2002. Improvement of rhizosphere aggregate stability of afforested semiarid plant species subjected to mycorrhizal inoculation and compost addition. Geoderma, 108 (1-2), 133-144, https://doi.org/10.1016/S0016-7061(02)00130-1

Celik I., Turgut M.M., and Acir N., 2012. Crop rotation and tillage effects on selected soil physical properties of a Typic Haploxerert in an irrigated semi-arid Mediterranean region. Int. J. Plant Prod., 6(4), 457-480,

https://doi.org/10.22069/ijpp.2012.760

Chenu C. and Cosentino D., 2011. Microbial regulation of soil structural dynamics. In: The architecture and biology of soils: life in inner space (Eds K. Ritz, I.M. Young). Oxford UniversityPress,37-70,https://doi.org/10.1079/9781845935320.0037

Childs E.C., 1940. The use of soil moisture characteristics in soil studies. Soil Sci., 50(4), 239-252.

https://doi.org/10.1097/00010694-194010000-00001

Collis-George N. andFigueroa B.S., 1984. The use of high energy moisture characteristic to assess soil stability. Aust. J. Soil Res., 22(3), 349-356, https://doi.org/10.1071/SR9840349

Dexter A.R., 2004. Soil physical quality. Part I: Theory, effects of soil texture, density and organic matter, and effects on root growth. Geoderma, 120, 201-214, https://doi.org/10.1016/j.geoderma.2003.09.004

Duchicela J., Sullivan T.S., Bontti E., and Bever J.D., 2013. Soil aggregate stability increase is strongly related to fungal community succession along an abandoned agricultural field chronosequence in the Bolivian Altiplano. J. Appl. Ecol., 50(5), 1266-1273, https://doi.org/10.1111/1365-2664.12130

Duiker S.W., 2006. Aggregation. In Encyclopaedia of Soil Science. Pennsylvania State Univ., University Park, PA, USA

Emami H. and Astaraei A.R., 2012. Effect of organic and inorganic amendments on parameters of water retention curve, bulk density and aggregate diameter of a saline-sodic soil. J. Agric. Sci. Technol., 14(7), 1625-1636.

Farahani E., Emami H., Fotovat A., Khorassani R., and Keller T., 2020. Soil available water and plant growth in relation to K: Na ratio. Geoderma, 363, 114173, https://doi.org/10.1016/j.geoderma.2020.114173

Farahani E., Emami H., Keller T., Fotovat A., and Khorasani R., 2018. Impact of monovalent cations on soil structure, Part I: Results of an Iranian soil. Int. Agrophys., 32, 57-67, https://doi.org/10.1515/intag-2016-0091 
Gee G.W. and Bauder J.W., 1986. Particle-size distribution. In: Methods of Soil Analysis. Part 1. Physical and mineralogical methods (Ed. A. Klute), Monograph 9. ASA/SSSA, Madison, WI. 384-411.

Gholoubi A., Emami H., and Caldwell T., 2019. Deforestation effects on soil aggregate stability quantified by the high energy moisture characteristic method. Geoderma, 355, 113919, https://doi.org/10.1016/j.geoderma.2019.113919

Guidi P., Falsone G., Mare B.T., and Vianello G., 2013. Relationships between soil microbial biomass, aggregate stability and aggregate associated-C: a mechanistic approach. EQA-Int. J. Environ. Qual., 12, 1-16, https://doi.org/10.6092/issn.2281-4485/4125

Gwenzi W., Gotosa J., Chakanetsa S., and Mutema Z., 2009. Effects of tillage systems on soil organic carbon dynamics, structural stability and crop yields in irrigated wheat (Triticum aestivum L.)-cotton (Gossypium hirsutum L.) rotation in semi-arid Zimbabwe. Nutr. Cycl. Agroecosystems, 83(3), 211-221, https://doi.org/10.1007/s10705-008-9211-1

Hosseini F., Mosaddeghi M.R., Hajabbasi M.A., and Sabzalian M.R., 2015. Influence of tall fescue endophyte infection on structural stability as quantified by high energy moisture characteristic in a range of soils. Geoderma, 249, 87-99, https://doi.org/10.1016/j.geoderma.2015.03.013

Jenkinson D.S. and Powlson D.S., 1976. The effects of biocidal treatments on metabolism in soil-I. Fumigation with chloroform. Soil Biol. Biochem., 8(3), 167-177, https://doi.org/10.1016/0038-0717(76)90005-5

Kara O. and Baykara M.,, 2014. Changes in soil microbial biomass and aggregate stability under different land uses in the northeastern Turkey. Environ. Monit. Assess., 186(6), 3801-3808, https://doi.org/10.1007/s10661-014-3658-0

Kemper W.D. and Rosenau R.C., 1986. Aggregate stability and size distribution. In: Methods of soil analysis. Part 1. Physical and mineralogical methods (Ed. A. Klute). Agron. Monogr. 9. ASA/SSSA, Madison, WI, 425-442, https://doi.org/10.2136/sssabookser5.1.2ed.c17

Levy G.J. and Mamedov A.I., 2002. High-energy-moisturecharacteristic aggregate stability as a predictor for seal formation. Soil Sci. Soc. Am. J., 66(5), 1603-1609, https://doi.org/10.2136/sssaj2002.1603

Mamedov A.I. and Levy G.J., 2013. High energy moisture characteristics: linking between some soil physical processes and structure stability. In: Quantifying and Modeling Soil Structure Dynamics (Eds S. Logsdon et al.). Soil Sci. Soc. Am., Madison, WI. pp. 41-74,

https://doi.org/10.2134/advagricsystmodel3.c3

Mamedov A.I., Bar-Yosef B., Levkovich I., Rosenberg R., Silber A., Fine P., and Levy G.J., 2014. Amending soil with sludge, manure, humic acid, orthophosphate and phytic acid: effects on aggregate stability. Soil Res., 52 (4), 317-326, https://doi.org/10.1002/ldr.2474

Mamedov A.I., Huang C.H., Aliev F.A., and Levy G.J., 2017. Aggregate stability and water retention near saturation characteristics as affected by soil texture, aggregate size and polyacrylamide application. Land Degr. Dev., 28(2), 543-552, https://doi.org/10.1002/ldr.2509

Mamedov A.I., Tsunekawa A., Tsubo M., Fujimaki H., Ekberli I., Şeker C., Öztürk H.S., Cerdà A., and Levy G.J., 2020. Structure stability of cultivated soils from semi-arid region: Comparing the effects of land use and anionic polyacrylamide application. Agronomy, 10(12), 2010, https://doi.org/10.3390/agronomy10122010
Mamedov A.I., Wagner L.E., Huang C., Norton L.D., and Levy G.J., 2010. Polyacrylamide effects on aggregate and structure stability of soils with different clay mineralogy. Soil Sci. Soc. Am. J., 74(5), 1720-1732, https://doi.org/10.2136/sssaj2009.0279

Moshiri F., Samavat S., and Balali M.R., 2017. Soil organic carbon: a key factor of sustainable agriculture in Iran. In: Global Symposium on Soil Organic Carbon, Rome. 21-23.

Pierson F.B. and Mulla D.J., 1989. An improved method for measuring aggregate stability of a weakly aggregated loessial soil. Soil Sci. Soc. Am. J., 53(6), 1825-1831, https://doi.org/10.2136/sssaj1989.03615995005300060035x

Poch R.M. and Antunez M., 2010. Aggregate development and organic matter storage in Mediterranean mountain soils. Pedosphere, 20(6), 702-710, https://doi.org/10.1016/S1002-0160(10)60060-4

Richards L.A., 1954. Diagnosis and Improvement of Saline and Alkali Soils. USDA. Agriculture Handbook, 60. United States Salinity Laboratory, Washington.

Silva É.A. D., Oliveira G.C. D., Silva B.M., Carducci C.E., Avanzi J.C., and Serafim M.E., 2014. Aggregate stability by the" high energy moisture characteristic" method in an oxisol under differentiated management. Revista Brasileira de Ciência do Solo, 38(5), 1633-1642, https://doi.org/10.1590/S0100-06832014000500028

Singer M.J. and Munns D.N., 2002. Soils: An Introduction. Pearson Education, Inc., Upper Saddle River, NJ.

Soil Survey Staff., 2014. Keys to soil taxonomy. US Department of Agriculture, Natural Resources Conservation Service, Washington, DC.

Sparks D.L., Fendorf S.E., Zhang P.C., and Tang L., 1992. Kinetics and mechanisms of environmentally important reactions on soil colloidal surface. NATO Advanced Study Institute on Migration and Fate of Pollutants in Soils and Subsoils, May 24-June 5, Maratea, Italy, https://doi.org/10.1007/978-3-642-77862-9 7

Tisdall J.M., and Oades J.M., 1982. Organic matter and waterstable aggregates in soils. J. Soil Sci., 33: 141-163, https://doi.org/10.1111/j.1365-2389.1982.tb01755.x

Umer M.I. and Rajab S.M., 2012. Correlation between aggregate stability and microbiological activity in two Russian soil types. Eurasian J. Soil Sci., 1(1), 45-50.

Van Bavel C.H.M., 1950. Mean weight-diameter of soil aggregates as a statistical index of aggregation. Proc. Soil Sci. Soc. Am., 1949, 14, 20-23, https://doi.org/10.2136/sssaj1950.036159950014000C0005x

Walkley A. and Black I.A., 1934. An Examination of Degtjareff method for determining soil organic matter and a proposed modification of the chromic acid titration method. Soil Sci., 37, 29-37, https://doi.org/10.1097/00010694-193401000-00003

Wertebach T.M., Hölzel N., Kämpf I., Yurtaev A., Tupitsin S., Kiehl K., Kamp J., and Kleinebecker T., 2017. Soil carbon sequestration due to post-Soviet cropland abandonment: estimates from a large-scale soil organic carbon field inventory. Glob. Change Biol., 23(9), 3729-3741, https://doi.org/10.1111/gcb.13650

Wortman C.S., Shapiro C.A.and Tarkalson D.D., 2006. Composting manure and other organic residues. NebGuide G1315.

Wraith J.M. and Or D., 1998. Nonlinear parameter estimation using spreadsheet software. J. Nat. Resour. Life Sci. Educ., 27, 13-19, https://doi.org/10.2134/jnrlse.1998.0013

Wu J., Stephen Y., Cai L., Zhang R., Qi P., Luo Z., Li L., Xie J., and Dong B., 2019. Effects of different tillage and straw retention practices on soil aggregates and carbon and nitrogen sequestration in soils of the northwestern China. J. Arid Land. 11(4), 567-578, https://doi.org/10.1007/s40333-019-0065-y 
Wu X., Wei Y., Wang J., Wang D., She L., Wang J., and Cai C., Yamakura T. and Sahunalu P., 1990. Soil carbon/nitrogen ratio 2017. Effects of soil physicochemical properties on aggregate stability along a weathering gradient. Catena, 156, 205-215, https://doi.org/10.1016/j.catena.2017.04.017 as a site quality index for some South-east Asian forests. J. Trop. Ecol., 6(3), 371-377,

https://doi.org/10.1017/S0266467400004661 